\title{
Hydrogel depots for local co-delivery of osteoinductive peptides and mesenchymal stem cells
}

\author{
F. Raquel Maia ${ }^{\mathrm{a}, \mathrm{b}}$, Mariana Barbosa ${ }^{\mathrm{a}}$, David B. Gomes ${ }^{\mathrm{a}, \mathrm{b}}$, Nuno Vale ${ }^{\mathrm{c}}$, Paula Gomes ${ }^{\mathrm{c}}$, \\ Pedro L. Granja a,b,d , Cristina C. Barrias ${ }^{\mathrm{a}, *}$ \\ a INEB-Instituto de Engenharia Biomédica, Rua do Campo Alegre, $n .{ }^{\circ} 823,4150-180$ Porto, Portugal \\ ${ }^{\text {b } F E U P-F a c u l d a d e ~ d e ~ E n g e n h a r i a ~ U n i v e r s i d a d e ~ d o ~ P o r t o, ~ R u a ~ D r . ~ R o b e r t o ~ F r i a s ~ s / n, ~ 4200-465 ~ P o r t o, ~ P o r t u g a l ~}$ \\ c CIQ-UP, Departamento de Química e Bioquímica, Faculdade de Ciências, Universidade do Porto, Rua do Campo Alegre 687, 4169-007 Porto, Portugal \\ d ICBAS-Instituto de Ciências Biomédicas Abel Salazar, Universidade do Porto, Rua de Jorge Viterbo Ferreira n. ${ }^{\circ} 228,4050-313$ Porto, Portugal
}

\section{A R T I C L E I N F O}

\section{Article history:}

Received 21 February 2014

Accepted 19 June 2014

Available online 27 June 2014

Keywords:

Injectable alginate hydrogels

Osteoinductive peptides

Co-delivery systems

Mesenchymal stem cells

Guided differentiation

Bone regeneration

\begin{abstract}
A B S T R A C T
The outcome of cell-based therapies can benefit from carefully designed cell carriers. A multifunctional injectable vehicle for the co-delivery of human mesenchymal stem cells (hMSCs) and osteoinductive peptides is proposed, to specifically direct hMSCs osteogenic differentiation. The osteogenic growth peptide (OGP) inspired the design of two peptides, where the bioactive portion of OGP was flanked by a protease-sensitive linker, or its scrambled sequence, to provide faster and slower release rates, respectively. Peptides were fully characterized and chemically grafted to alginate. Both OGP analogs released bioactive fragments in vitro, at different kinetics, which stimulated hMSCs proliferation and osteogenesis. hMSCs-laden OGP-alginate hydrogels were tested at an ectopic site in a xenograft mouse model. After 4 weeks, OGP-alginate hydrogels were more degraded and colonized by vascularized connective tissue than the control (without OGP). hMSCs were able to proliferate, migrate outward the hydrogels, produce endogenous extracellular matrix and mineralize it. Moreover, OGP-groups stimulated hMSCs osteogenesis, as compared with the control. Overall, the ability of the proposed platform to direct the fate of transplanted hMSCs in loco was demonstrated, and OGP-releasing hydrogels emerged as a potentially useful system to promote bone regeneration.
\end{abstract}

(c) 2014 Elsevier B.V. All rights reserved.

\section{Introduction}

Hydrogels show great potential as cell vehicles for minimally invasive bone regeneration therapies. These materials form highly hydrophilic 3D networks that recreate some features of native extracellular matrices (ECM), providing adequate cellular microenvironments where the exchange of nutrients, oxygen and metabolites with the extracellular milieu is facilitated. Compared to direct bolus injection at the injury site, often associated with poor cell survival, the preentrapment of cells in a hydrogel delivery vehicle may improve viability by providing physical protection, biochemical and biomechanical survival signals, and scaffolding [1,2]. It also helps localizing cells to the targeted area, increasing the chance of post-transplantation cell retention and engraftment, and affording a template for new tissue formation [1,2]. Hydrogels can be further decorated with specific cellinstructive cues aimed at directing the phenotype of entrapped cells. Therapeutic approaches aiming at driving mesenchymal stem cells (MSCs) fate in a controlled manner, namely by promoting their

\footnotetext{
* Corresponding author at: Rua do Campo Alegre, 823; 4150-180 Porto, Portugal. Tel.: + 351226074900 .

E-mail address: ccbarrias@ineb.up.pt (C.C. Barrias).
}

differentiation into bone-forming cells through the co-delivery of osteoinductive compounds, are promising for bone healing applications $[1,2]$.

Strategies involving the use of small compounds, such as peptides, can be advantageous as compared to more complex biomolecules, by leading to less expensive, more stable and easily tunable biomaterial formulations [2,3]. Up to now, different types of osteoinductive peptides have been proposed [4]. In this study, we evaluated the potential of OGP, a naturally occurring tetradeca-peptide identical to the C-terminus of histone H4 (residues 89-102, ALKRQGRTLYGFGG), which is present in plasma at micromolar concentrations [5-8]. The physiologically active form of OGP, which corresponds to its C-terminal pentapeptide sequence YGFGG (OGP10-14), is generated from full-length OGP by proteolytic cleavage [5]. This fragment directly interacts with cell membrane receptors, activating the MAP kinase, Src and RhoA signaling pathways [9-11]. Upon intravenous administration, synthetic OGP and OGP10-14 were shown to promote increased bone mass and fracture healing in vivo [12,13]. In vitro, OGP peptides were shown to increase the proliferation of osteoblastic-like cells and MSC and accelerate osteogenesis $[14,15]$. In pursuit for superior osteoinductive compounds for bone regeneration therapies, OGP has provided a useful basis for engineering additional OGP analogs with enhanced bioactivity, stability 
and bioavailability. This includes the design of different peptide sequences to be used in free soluble forms [8], as well as more complex systems with physically or chemically immobilized OGP for local administration [16-18]. In this context, the aim of this study was to develop protease-responsive delivery systems for OGP analogs, which could simultaneously act as injectable hMSCs vehicles, for minimally invasive healing of small bone defects. Among the numerous proteases that can be selected to trigger enzyme-activated drug release, those belonging to the metalloproteinase (MMP) family are particularly attractive. MMPs actively participate in ECM remodeling and degradation, having a key role in wound healing and tissue regeneration, and some are constitutively expressed by both naïve and differentiated hMSCs [19,20]. Here, different OGP analogs were designed, by flanking the YGFGG Nterminus with the MMP-substrate PVGLIG or its scrambled sequence GIVGPL [20]. Both were chemically grafted to alginate, a natural polysaccharide with the ability to form hydrogels in situ, which has been extensively used as a delivery vehicle for entrapped cells [21-23]. We hypothesized that in the presence of specific MMPs, in particular MMP-2 [20,24], the bioactive YGFGG fragment would be released from the hydrogel upon enzymatic cleavage of the PVGLIG sequence, while it would remain mostly immobilized when using the scrambled linker. Once implanted, such systems may, thus, provide localized OGP delivery for variable time periods, remaining in close proximity to the targeted host cells at the injury site. If OGP-functionalized hydrogels are simultaneously used as hMSCs carriers, the released peptides might act on the transplanted cells and specifically guide their differentiation along the osteoblastic lineage. In this study, the designed OGP analogs and OGP-alginate conjugates were firstly characterized at different levels, and then used for the preparation of OGP-alginate hydrogels. The in vivo performance of hMSCs-laden hydrogels was evaluated after 4weeks of implantation at an ectopic site in a xenograft mouse model.

\section{Materials and methods}

\subsection{Peptides}

\subsubsection{Synthesis and characterization of OGP analogs}

Different OGP-based oligopeptide sequences, hereafter designated by OGP1, OGP2 and OGP3 (full sequences and additional information are depicted in Table 1) were synthesized by solid-phase peptide synthesis (SPPS) using the Fmoc/tBu protection scheme [25]. The polymeric support selected, Fmoc-Gly-Wang resin $(1 \mathrm{mmol} / \mathrm{g}$, Iris Biotech), was an hydroxymethylated resin pre-loaded with the Fmoc-protected C-terminal amino acid; it was first deprotected by a $20 \%$ solution of piperidine (Sigma-Aldrich) N,N-dimethylformamide (DMF, Sigma-Aldrich). After washing with DMF and dichloromethane (DCM, Sigma-Aldrich), the next Fmoc-protected amino acid (Fmoc-AA-OH, Novabiochem or Bachem) was coupled to the Gly-Wang resin by means of DIPCDI (Fluka) coupling reagent. Then, the Fmoc protecting group was removed again with $20 \%$ piperidine in DMF and, after resin washing with DMF and

Table 1

Different peptide sequences used and their characteristics. ${ }^{a}$

\begin{tabular}{llcll}
\hline Name & Amino acid sequence & $\begin{array}{l}\text { Mw } \\
\mathrm{g} / \mathrm{mol}\end{array}$ & $\begin{array}{l}\text { Purity } \\
\%\end{array}$ & $\begin{array}{l}\text { Grafted } \\
\text { amount } \\
\mathrm{mg} / \mathrm{g} \mathrm{Alg}\end{array}$ \\
\hline OGP1 & GGGYGFGG & 671 & 90 & 11.4 \\
OGP2 & GGPVG $\downarrow$ LIGGYGFGG & 1207 & 92 & 20.5 \\
FRET-OGP2 & (Abz)-GGPVG $\downarrow$ LIGGYGFGG-Q-(EDDnp) & 1662 & $\geq 95$ & n.a. \\
OGP3 & GGGIVGPLGYGFGG & 1207 & 99 & 31.0 \\
FRET-OGP3 & (Abz)-GGGIVGPGYGFGG-Q-(EDDnp) & 1662 & $\geq 95$ & n.a. \\
RGD & GGGGRGDSP & 759 & 96 & 15.9
\end{tabular}

a Alg-alginate; Abz-ortho-aminobenzoyl; EDDnp-N-(2,4-dinitrophenyl)ethylenediamine; F-phenylalanine; FRET-fluorescence resonance energy transfer; Gglycine; I-isoleucine; L-leucine; n.a.-not applicable; P-proline; V-valine; Y-tyrosine. In MMP-sensitive sequences the cleavage site is indicated by an arrow $(G \downarrow L)$. In all OGP analogs the bioactive YGFGG fragment is underlined.
DCM, the following Fmoc-AA-OH was coupled to the peptidyl-resin as before. This process was repeated in the $\mathrm{C} \rightarrow \mathrm{N}$ direction until the full amino acid sequence was assembled. Peptide cleavage from the resin occurred in acidic conditions using trifluoroacetic acid (TFA, Sigma-Aldrich), triisopropylsilane (TIS, Sigma-Aldrich) and $\mathrm{H}_{2} \mathrm{O}$ (95:2.5:2.5) cocktail $[25,26]$. Liquid chromatography-mass spectroscopy (LC-MS) was used to check the molecular weight of the synthesized peptides. Samples were prepared in methanol and all data were collected in positive ion mode, in a LCQ-Deca XP LC-MS system from ThermoFinnigan, equipped with both a diode-array detector (DAD) detector and an electrospray ionization-ion trap mass spectrometer (ESI/IT MS). A high pressure LC (HPLC) method was established for the quantification of the peptides purity on a LaChrom Elite system (Hitachi-Merck) equipped with a quaternary pump a thermostatted (Peltier) automated sampler and a DAD. A Purospher Star RP-C18 column (particle size $5 \mu \mathrm{m}, 4.6 \mathrm{~mm}$ i.d. $\times 150 \mathrm{~mm}$ length) was used for the separations. The solvents used for the analysis were: solvent A ( $0.05 \%$ TFA in water) and solvent B (HPLC-grade acetonitrile). The mobile phase consisted of a linear gradient of 0 to $100 \%$ of $B$ in $A$ in $30 \mathrm{~min}$. The flow rate was set at $1 \mathrm{~mL} / \mathrm{min}$ and the analytes were detected at $220 \mathrm{~nm}$. When necessary (if purity $<90 \%$ ), peptides were purified by preparative reverse phase LC at medium pressure (RP-MPLC). The elution conditions consisted of a linear gradient from $20 \%$ to $30 \%$ of acetonitrile in water. The effluent was monitored at an absorbance of $220 \mathrm{~nm}$, absorbing peaks were collected, peptides were lyophilized and analyzed by HPLC and LC-MS. Assessment of the peptides' purity by HPLC was based on the calculation of the relative \% of the peptide's peak area as compared to the sum of the areas of all detected peaks. FRET peptides, kindly provided by $\mathrm{Dr}^{\mathrm{a}}$ Maria Aparecido (UNIFESP, Brazil), were used for some assays. These incorporated an orthoaminobenzoyl (Abz) fluorescent group and an N-(2,4-dinitrophenyl)ethylenediamine (EDDnp) quenching group at each side, as donor/ acceptor pair, and also a $Q$ residue as a requirement for SPPS (Table 1). FRET-peptides were synthesized using the Fmoc-procedure in an automated solid-phase peptide synthesizer (PSSM 8 system from Shimadzu-Tokyo, Japan), as described elsewhere [27]. Peptides were purified by semi-preparative HPLC, and their molecular weight and purity were checked by amino acid analysis and matrix-assisted laser desorption/ionization-time of flight (MALDI-TOF) MS, using a Microflex-LT mass spectrometer (Bruker-Daltonics, Billerica, MA, USA). The concentration of the FRET substrates was obtained by colorimetric determination of the EDDnp group $\left(\varepsilon=17300 \mathrm{M}^{-1} \mathrm{~cm}^{-1}\right.$ at $365 \mathrm{~nm}$ ), using peptide solutions at $1 \mathrm{mg} / \mathrm{mL}$ in DMF:Water (1:1).

\subsubsection{Enzymatic cleavage of free OGP analogs}

Peptide solutions were prepared at $828 \mu \mathrm{M}$ in Dulbecco's phosphatebuffered saline (DPBS) containing calcium and magnesium (Invitrogen, Carlsbad, CA). Recombinant active human MMP-2 (Calbiochem, $25 \mathrm{nM}$ ) was added to each peptide solution. In control samples, the same volume of DPBS was added instead of the enzyme. After $24 \mathrm{~h}$ of incubation at $37{ }^{\circ} \mathrm{C}$, MMP-2 was removed by ultrafiltration (Amicon Centrifugal Filter, MWCO $10 \mathrm{kDa}$, Millipore) for 2-5 min at 14,000 $\times$ g, and the filtrates were recovered for analyses. The extent of peptide cleavage was estimated using the fluorescamine assay [28]. Briefly, each solution was placed $(50 \mu \mathrm{L})$ into the wells of a 96 black-well plate and reacted with $7 \mu \mathrm{L}$ of $21.6 \mathrm{mM}$ fluorescamine (Sigma). Fluorescence was measured with an excitation wavelength of $400 \mathrm{~nm}$ and an emission wavelength of $460 \mathrm{~nm}$ in a microplate reader (SynergyTM Mx, Biotek). All measurements were made using at least $\mathrm{n}=3$ replicates, and are reported in relative fluorescence units (RFUs). The molar masses of intact and digested peptides $(t=24 \mathrm{~h}$ ) were determined by LC-MS analysis. The kinetics of peptide cleavage by MMP-2 was analyzed using FRET peptides. These were incubated in DPBS and fetal bovine serum (FBS; Gibco; $10 \% \mathrm{v} / \mathrm{v}$ in DPBS), with or without MMP-2 (10 nM). Each solution was placed in triplicate $(50 \mu \mathrm{L})$ into the wells of a 96 black-well plate maintained on ice, and the peptides were added to a final concentration of $5 \mu \mathrm{M}$. The plate was then placed in a thermostatized $\left(37^{\circ} \mathrm{C}\right)$ 
microplate reader and fluorescence was continuously measured $(E x=320 \mathrm{~nm}, \mathrm{Em}=420 \mathrm{~nm}$ ) along the first hour of incubation, and then again after $48 \mathrm{~h}$ at $37{ }^{\circ} \mathrm{C}$. All measurements were made using at least $\mathrm{n}=3$ replicates.

\subsubsection{Effect of peptides on hMSCS proliferation and osteogenic differentiation}

Human mesenchymal stem cells (hMSCs) were purchased from Lonza (PT-2501; Lot No. 6F4392; Age: 19, Male) and routinely cultured in basal medium (BM) consisting on low-glucose Dulbecco's Modified Eagle Medium (DMEM) with glutamax (Gibco), supplemented with $1 \% \mathrm{v} / \mathrm{v}$ Penicillin/Streptomycin (Gibco) and 10\% v/v FBS (MSC-qualified, Gibco). Cultures were maintained at $37{ }^{\circ} \mathrm{C}$ under a humidified atmosphere of $5 \% \mathrm{v} / \mathrm{v} \mathrm{CO}_{2}$ in air, with the culture medium changed twice a week, and were trypsinized at $70 \%$ confluency. For these studies, hMSCs (P5) were seeded at 3000 cells $/ \mathrm{cm}^{2}$ in 24-well tissue culture polystyrene (TCPS) plates. Cell proliferation was analyzed using the tritiated thymidine $\left({ }^{3} \mathrm{H}-\mathrm{TdR}\right)$ incorporation assay. Stock solutions of free peptides were sterilized by filtration $(0.2 \mu \mathrm{m})$ and then added at a final concentration of $10^{-5} \mathrm{M}$ or $10^{-12} \mathrm{M}$ to culture medium without FBS. The control consisted on culture media with $0.5 \% \mathrm{v} / \mathrm{v}$ FBS. ${ }^{3} \mathrm{H}-\mathrm{TdR}$ was added to the different media at a final concentration of $1 \times 10^{-3} \mathrm{Ci} / \mathrm{mmol}$, and cells were incubated for $24 \mathrm{~h}$ prior to analysis. Cells were detached and treated with trichloroacetic acid $(5 \% \mathrm{v} / \mathrm{v}, 10 \mathrm{~min})$ to precipitate nucleic acids. The precipitates were then dissolved with $\mathrm{NaOH}(1 \mathrm{M})$ and scintillation liquid (PerkinElmer) was added. After $1 \mathrm{~h}$ of incubation in the dark, samples were analyzed in a scintillation counter (MicroBeta Trilux, PerkinElmer). For analysis of osteogenic differentiation, hMSCs were cultured for 7 days under basal and osteoinductive conditions in 24-well TCPS plates. The osteogenic medium (OM) consisted of low glucose DMEM supplemented FBS (10\% v/v, pre-selected batch, PAA), dexamethasone (Sigma, $100 \mathrm{nM}$ ), $\beta$-glycerophosphate (Sigma, $10 \mathrm{mM}$ ) and 2-phosphoL-ascorbic acid (Sigma, $0.05 \mathrm{mM}$ ). Free peptides were added at a final concentration of $10^{-5} \mathrm{M}$ or $10^{-12} \mathrm{M}$ to both media. Medium was renewed every 4 days and fresh peptides were added each time. At day 7, cell monolayers were stained for alkaline phosphatase (ALP) activity. After fixation with $4 \% \mathrm{v} / \mathrm{v}$ paraformaldehyde (PFA) in PBS for $20 \mathrm{~min}$, cells were incubated for $30 \mathrm{~min}$ in Naphthol AS-MX phosphate/Fast Violet B salt at $37{ }^{\circ} \mathrm{C}$ in the dark. After washing, stained monolayers were airdried and observed under an inverted microscope (Axiovert $200 \mathrm{M}$, Zeiss). In order to quantify ALP activity, cells were lysed and incubated with the chromogenic substrate p-nitrophenol phosphate $(2 \mathrm{mM}$ in $0.2 \mathrm{M}$ bicarbonate buffer, $\mathrm{pH} 10 ; 0.05 \% \mathrm{v} / \mathrm{v}$ Triton X-100 and $4 \mathrm{mM}$ $\mathrm{MgCl}_{2} ; 1 \mathrm{~h}$ at $37^{\circ} \mathrm{C}$ ). Absorbance was read at $405 \mathrm{~nm}$ in a microplate reader (Biotek Synergy MX), and converted into product concentrations using a calibration curve built with serially diluted p-nitrophenol standards. ALP activity was normalized to total protein content, calculated using the bicinchoninic acid assay (BCA Total Protein assay, Pierce), and expressed as $\mathrm{nmol} / \mathrm{min} / \mathrm{mg}$ protein.

\subsection{Peptide-alginate hydrogels}

\subsubsection{Synthesis of peptide-alginate conjugates}

PRONOVA ultrapure sodium alginates LVG and VLFG (hereafter designated as high molecular weight, HMW and low molecular weight, LMW; respectively) with a high guluronic acid content (68\% and 67\%, respectively) were purchased from FMC Biopolymers. Their molecular weights, measured by TripleSEC as described in [22], were $1.5 \times$ $10^{5} \mathrm{Da}(\mathrm{HMW})$ and $2.5 \times 10^{4} \mathrm{Da}(\mathrm{LMW})$. The HMW alginate was partially oxidized with sodium periodate $[29,30]$. Aqueous carbodiimide chemistry was used to connect peptide N-terminal amino groups to alginate carboxyl groups via a peptide bond [31]. Briefly, LMW and HMW alginate solutions at 1 wt.\% in MES buffer ( $0.1 \mathrm{M}, 0.3 \mathrm{M} \mathrm{NaCl}$, pH 6.5, Sigma) were prepared and stirred ON at RT. N-hydroxy-sulfosuccinimide (sulfoNHS, Pierce) and 1-ethyl-(dimethylaminopropyl)-carbodiimide (EDC, Sigma, $27.4 \mathrm{mg} / \mathrm{g}$ alginate) at a molar ratio of $1: 2$ were sequentially added to the solution, followed by peptides. OGP analogs were conjugated to LMW alginate, and cell-adhesion RGD peptides (GenScript, USA) were conjugated to HMW alginate. Alginate samples that were subjected to the same procedure but without the addition of peptides were used as controls (hereafter designated $\mathrm{HO}$ and $\mathrm{L} 0$ ). The modified alginates were purified by dialysis (MWCO 3500 membrane, Spectrumlabs) against distilled water and saline, filtered $(0.2 \mu \mathrm{m})$, freeze-dried and stored at $-20^{\circ} \mathrm{C}$ until used. The grafting efficiency was obtained using the BCA assay [20]. Absorbance readings were converted into peptide concentrations using a calibration curve built with serially diluted peptide solutions in $1 \mathrm{wt} . \%$ of LO or $\mathrm{H0}$ alginate. Grafted amounts (mg peptide per gram of alginate) for the different peptides are depicted in Table 1.

\subsubsection{Preparation of peptide-alginate hydrogels: films and cell-laden $3 D$ matrices}

Hydrogel-precursor solutions with a previously optimized bimodal molecular weight composition [20,32] were prepared by combining HMW alginate (modified with RGD) and LMW alginate (modified with OGP analogs) at a 1:1 volume ratio and a final polymer concentration of $2 \mathrm{wt}$.\%. For adjusting the final amount of each peptide ( $150 \mu \mathrm{M}$ RGD, $190 \mu \mathrm{M}$ OGP analogs) unmodified and peptide-modified alginates were combined at different ratios and dissolved $\mathrm{ON}$ in $\mathrm{NaCl}$ (Sigma, 0.9 wt.\%). Alginate hydrogel films (OGP/RGD-Alg and RGD-Alg) were prepared by spin-coating, as described in the next section. To obtain cell-laden hydrogels for in vivo studies, hMSCs were added to an alginate solution $\left(15 \times 10^{6}\right.$ cells $\left./ \mathrm{mL}\right)$ with $\mathrm{CaCO}_{3}$ (Fluka, $\mathrm{Ca}^{2+} / \mathrm{COO}^{-}$ molar ratio $=0.288$ ) and $\delta$-gluconolactone (GDL, Sigma, $\mathrm{Ca}^{2+} / \mathrm{GDL}$ molar ratio $=0.125)$, and the mixture was loaded $(85 \mu \mathrm{L})$ into a $\mathrm{QGel}^{\mathrm{TM}}$ 3D disc caster and allowed to crosslink (20 min, RT) as previously described [33]. Prior to use, alginate and GDL solutions were sterilized by filtration $(0.2 \mu \mathrm{m})$, while $\mathrm{CaCO}_{3}$ was sterilized by dry heat $\left(160{ }^{\circ} \mathrm{C}\right.$, $120 \mathrm{~min}$ ). Hydrogels were then prepared under aseptic conditions (laminar flow hood). To analyze the release of OGP from alginate hydrogels, OGP-Alg hydrogel discs were incubated in DPBS with or without MMP-2 (60 nM) and incubated at $37{ }^{\circ} \mathrm{C}$. The extent of MMP2triggered peptide cleavage (OGP release) was estimated at 0, 24 and $72 \mathrm{~h}$ using the fluorescamine assay, as described for the free peptides.

\subsection{3. hMSCs proliferation on peptide-alginate hydrogels}

To prepare alginate films, $100 \mu \mathrm{L}$ of $1.5 \mathrm{wt} . \%$ peptide-alginate solutions (with the same composition of the gel precursor solutions described in Section 2.2.1) were deposited onto round plastic coverslips $(13 \mathrm{~mm})$, which had been previously treated with positively-charged poly-D-lysine (30 min in $0.1 \mathrm{mg} / \mathrm{mL}$ solution, followed washing and drying) to improve surface-adhesion and retention of negativelycharged alginate films. Samples were spun for $1 \mathrm{~min}$ at $9000 \mathrm{rpm}$ (SCS Cookson Electronics Spincoater model G3P-8) to ensure a homogeneous distribution of the polymer. Films were then crosslinked with calcium (0.1 $\mathrm{M} \mathrm{CaCl}_{2}, 0.01 \mathrm{wt}$ \% $\mathrm{NaN}_{3}, 10 \mathrm{~min}$ ). Coverslips were transferred to pHEMA-treated 24-well cell culture plates, washed twice with sterile distilled water and culture medium, and seeded with hMSCs at 20000 cells $/ \mathrm{cm}^{2}$. At each time point, ${ }^{3} \mathrm{H}$-TdR was added to the medium $\left(1 \times 10^{-3} \mathrm{Ci} / \mathrm{mmol}\right)$ and cells were incubated for $24 \mathrm{~h}$ prior to analysis. At $24 \mathrm{~h}, 48 \mathrm{~h}$ and $72 \mathrm{~h}$, cells were recovered and analyzed as described above.

\subsection{In vivo studies with hMSCs-laden peptide-alginate hydrogels}

\subsubsection{Subcutaneous implantation in immunodeficient mice}

All animal experiments were conducted following the protocols approved by the Ethics Committee of the Portuguese Official Authority on Animal Welfare and Experimentation (DGV). Severe combined immunodeficient (SCID) male mice (CB17/Icr-Prkdc scid/Crl, C17SSMA04S, Charles River, Spain) with 6 -week of age were used as recipients. Animals were housed at $22{ }^{\circ} \mathrm{C}$ with a $12 \mathrm{~h}$ light/dark cycle and had ad libitum access to water and food. Analgesics (Butorfanol) were 
administrated 30 min prior to surgery. The animals were anesthetized by inhalation of isoflurane, which was continuously delivered over the course of surgery. The dorsal surgical sites were shaved and sterilized. Single incisions were made and subcutaneous pockets were created for the insertion of hMSCs-laden hydrogel discs ( $8.5 \mathrm{~mm}$ diameter, $1.5 \mathrm{~mm}$ height). Three groups were tested: OGP2/RGD-Alg, OGP3/RGD-Alg and RGD-Alg (control), and one of each was placed in each mouse ( $\mathrm{n}=8$ mice, 3 discs per mouse). After implantation, incisions were closed with sutures and analgesics were administrated $(0.05 \mathrm{mg}$ Buprenorphine $\mathrm{HCl}$ per $\mathrm{kg}$ ). Animals were routinely monitored for general appearance, activity, and healing of the implant sites, and were euthanized after 4 weeks for implant retrieval. No mice were lost during the study.

\subsubsection{Histology}

After explantation, collected samples that included the entire hydrogel discs and some adjacent tissues were fixed in PFA $\left(4 \mathrm{wt} . \%, \mathrm{ON}\right.$ at $\left.4{ }^{\circ} \mathrm{C}\right)$ and paraffin embedded. Three-micrometer cross-sections were obtained from 2 to 3 standardized transversal planes using a Thermo Scientific HM550 microtome.

2.3.2.1. Histochemical staining. For analysis of alginate degradation/host tissue invasion, sections were stained with Safranin-O/Light-Green (Sigma, hematoxylin was used as counterstain), and glass slides ( $\mathrm{n}=4$ mice, 2 slides per mouse) were digitalized using a scanner (NanoZoomer 2.0, Hamamatsu). In each, the total area of the implanted disc was first delineated and then images were analyzed and processed using MeVisLab software (Fraunhofer MEVIS, Bremen, Germany), in order to quantify the partial areas of residual alginate (\% orange area) vs. invasion tissue (\% blue/green area). Results are presented as average \% of host tissue area. Collagen deposition was detected using the Masson's trichrome staining (Sigma, hematoxylin was used as counterstain), and calciumrich regions (mineralization) were detected using the alizarin red staining (Sigma). Images were obtained using a Zeiss Axiovert $200 \mathrm{M}$ inverted microscope.

2.3.2.2. Immunolabeling. Expression of collagen type I (COL1) was probed after antigen recovery with $10 \mathrm{mM}$ Tris/1 mM EDTA ( $\mathrm{pH} 9$ ) for $35 \mathrm{~min}$ at $95-98{ }^{\circ} \mathrm{C}$. Sections were incubated with rabbit anti-collagen I primary antibody (ab21285 Abcam, 1:200, ON at $4{ }^{\circ} \mathrm{C}$ ), and then with Alexa Fluor 594-labeled goat anti-rabbit IgG (Invitrogen-Molecular Probes, $1: 1000,1 \mathrm{~h}$ at RT) secondary antibody. For proliferating human/ mice cell detection, masked epitopes were exposed by treatment with sodium citrate $\left(10 \mathrm{mM}, \mathrm{pH} 6,35 \mathrm{~min}\right.$ at $\left.95-98{ }^{\circ} \mathrm{C}\right)$. Sections were incubated with mouse anti-human nuclei (MAB4383-3E1.3 Millipore, 1:400, ON at $4{ }^{\circ} \mathrm{C}$ ) and rabbit anti-Ki67 (ab15580 Abcam, 1:50) primary antibodies. This was followed by incubation with mouse-on-mouse biotinylated anti-mouse IgG (MOM Kit Vector, 1:1000, 10 min at RT), and finally with Alexa Fluor 555-streptavidin (Invitrogen-Molecular Probes, 1:500, 30 min at RT) and Alexa Fluor 488-labeled goat anti-rabbit IgG (Invitrogen-Molecular Probes, 1:1000, $30 \mathrm{~min}$ at RT), respectively. All sections were mounted in Fluoroshield ${ }^{\mathrm{TM}}$ with DAPI (Sigma). Control sections for each immunolabeling excluded primary antibody staining. From each disc, 4 whole-section images were obtained using Mosaixreconstruction (inverted microscope, Axiovert $200 \mathrm{M}$, Zeiss). In each image, the total amounts of $\mathrm{HuNu}+$ (human) and $\mathrm{HuNu}-$ (mouse) and Ki67 + (proliferating) cells per unit area were counted. Results are presented as average percentages of $\mathrm{HuNu}+\mathrm{Ki} 67+$ (proliferative, human) and $\mathrm{HuNu}$ - Ki67 + (proliferative, mouse) cells.

\subsection{3. $q R T-P C R$ analysis of hMSCs gene expression}

Total RNA was extracted from hMSCs recovered from 3D matrices ( $n=3$ ) using the RNeasy Mini Kit (Qiagen), as recommended by the manufacturer. Subsequently, $0.25 \mu \mathrm{g}$ of the total RNA were used for random hexamers first strand synthesis to generate single-stranded cDNA using the SuperScript First-strand synthesis system for q Real-Time PCR
(qRT-PCR) (Invitrogen). RNA quantification was performed by using a NanoDrop 1000 spectrophotometer. After the cDNA synthesis reaction, qRT-PCR was carried out in a total volume of $20 \mu \mathrm{L}$ of a mixture containing $1 \mu \mathrm{L}$ of cDNA ( $100 \mathrm{ng}$ of total RNA), $0.25 \mu \mathrm{M}$ of each forward and reverse primers, and $1 \times$ iQ SYBR Green Supermix (Bio-Rad). qRT-PCR experiments were run using an iQ5 (Bio-Rad) under the following conditions: $95^{\circ} \mathrm{C}$ for $3 \mathrm{~min}$, followed by 30 cycles at $94^{\circ} \mathrm{C}$ for $30 \mathrm{~s}, 60^{\circ} \mathrm{C}$ for $45 \mathrm{~s}$, and $72{ }^{\circ} \mathrm{C}$ for $30 \mathrm{~s}$, and the last step at $55^{\circ} \mathrm{C}$ for $10 \mathrm{~s}$. All reactions were performed in duplicate. After completion of the PCR cycling, melting curves, obtained by increasing the temperature from 60 to $96{ }^{\circ} \mathrm{C}$ in increments of $0.5{ }^{\circ} \mathrm{C}$, were examined to ascertain specificity of the PCR products. The housekeeping gene glyceraldehyde 3-phosphate dehydrogenase (GAPDH) was used as the endogenous assay control. Relative quantification of gene amplification by qRT-PCR was performed using the cycle threshold $(\mathrm{Ct})$ values and relative expression levels were calculated as follows: $2^{- \text {(Ct gene of interest-Ct GAPDHgene) }}$. The expression value for each target gene was normalized to the GAPDH value at each time point. The sequence and length of the primer pairs used is indicated in Table 2. For all primers used, the tool NCBI/Primer Blast was used to confirm specificity for human genes only and later corroborated by the absence of bands when tested in mouse cells.

\subsection{Statistics}

Statistical analyses were performed using GraphPad Prism 5.0 software version 5.0a. The non-parametric Mann-Whitney test was used to compare two groups, whereas comparison between more than two groups was performed using the Kruskal-Wallis test followed by Dunn's comparison test. The critical level of statistical significance chosen was $\mathrm{p}$ $<0.05$.

\section{Results and discussion}

\subsection{Enzymatic cleavage of free and alginate-conjugated OGP analogs}

Different OGP analogs were designed and synthesized by Fmoc/tBu SPPS, where the target bioactive fragment YGFGG was either flanked by a poly-G sequence (in OGP1), the MMP-cleavable substrate PVGLIG (in OGP2) [24], or the PVGLIG-scrambled sequence GIVGPL (in OGP3). Their molecular weight and purity were assessed by LC-MS and HPLC, respectively (Table 1 ). Mass spectra were acquired in the positive mode, and in all cases the base peaks at m/z 1207.67 and 1207.60 , respectively, were consistent with the peptide's molecular ion $\mathrm{M}+$. Base peaks were always significantly more intense than remaining peaks, revealing that the target peptides were obtained as the major synthesis product (purity $\geq 90 \%$, Table 1 ).

OGP2 and OGP3 were incubated with MMP-2, and enzymatic cleavage was analyzed by reacting fluorescamine with the peptide's primary amines to form fluorescent moieties [28]. The emitted fluorescence was

Table 2

Overview of primer pairs used for qRT-PCR. ${ }^{\mathrm{a}}$

\begin{tabular}{|c|c|c|c|}
\hline Gene name & Ref. sequence & Sequence of primers & $\begin{array}{l}\text { Length } \\
\text { (bp) }\end{array}$ \\
\hline GAPDH & NM_002046 & $\begin{array}{l}\mathrm{F}: 5^{\prime} \text {-AGCCACATCGCTCAGACAC-3' } \\
\text { R: 5'-GCCCAATACGACCAAATCC-3' }\end{array}$ & 66 \\
\hline ALP & ВС021289 & $\begin{array}{l}\text { F: 5'-AGAACCCCAAAGGCTTCTTC-3' } \\
\text { R: 5'-CTTGGCTTTTCCTTCATGGT-3' }\end{array}$ & 74 \\
\hline Runx2 & NM_001024630.2 & $\begin{array}{l}\text { F: 5'-GTGCCTAGGCGCATTTCA-3' } \\
\text { R: 5'-GCTCTTCTTACTGAGAGTGGAAGG-3' }\end{array}$ & 78 \\
\hline $\mathrm{OCN}$ & NM_199173.4 & $\begin{array}{l}\text { F: 5'-AGAGTCCAGCAAAGGTGCAG-3' } \\
\text { R: 5'-TCAGCCAACTCGTCACAGTC-3' }\end{array}$ & 171 \\
\hline VEGF $_{165}$ & AB021221.1 & $\begin{array}{l}\text { F: 5'-GCTGCACCCATGGCAGAA -3' } \\
\text { R: 5'-CTCCAGGCCCTCGTCATTG-3' }\end{array}$ & 204 \\
\hline
\end{tabular}

a ALP-alkaline phosphatase; F-forward primer; GAPDH-glyceraldehyde 3-phosphate dehydrogenase; OCN-osteocalcin; Runx2-runt-related transcription factor 2; $\mathrm{VEGF}_{165}-$ vascular endothelial growth factor 165; R-reverse primer. 
measured at the moment of incubation and after $24 \mathrm{~h}$, to estimate the accumulation of $\mathrm{N}$-amino termini in excess over that of the intact substrate, which in turn represents the extent of enzymatic cleavage. As predicted, no significant hydrolysis was detected in DPBS, and the OGP2 peptide was more efficiently cleaved by MMP-2 than OGP3, with a statistically significant 4-fold increase in RFU in relation to time $0(p=0.0286)$, and a 2 fold-increase in relation to OGP3 in MMP-2 $(\mathrm{p}=0.0286)$.

Both the intact peptides and their fragments, obtained after enzymatic digestion, were analyzed by LC-MS (Fig. 1). In both cases, only one major peak, corresponding to the original peptides ( $\mathrm{MW}=$


B

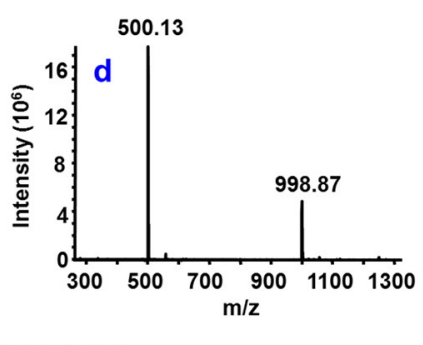

1d $\ln ($
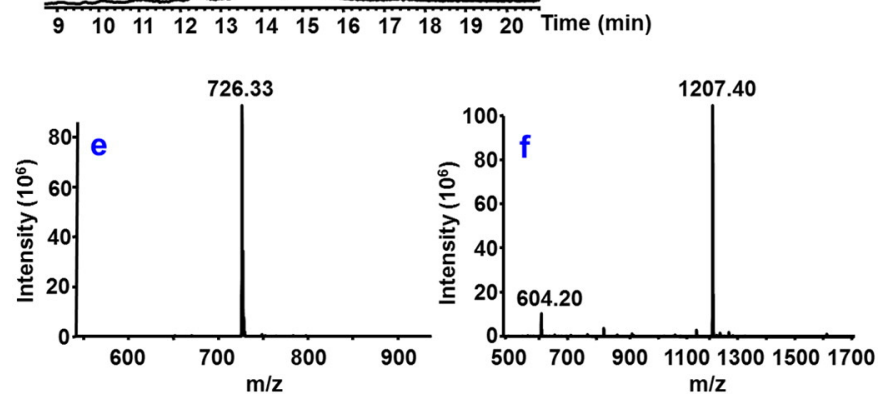

Fig. 1. LC-MS analysis of OGP-like peptides after $24 \mathrm{~h}$ of incubation with MMP-2. (A) OGP2: three peaks were chromatographically separated whose mass spectra were consistent with extensive MMP-2-mediated cleavage at the expected site, yielding fragments GGPVG (a, m/z $\left.[\mathrm{MH}]^{+}=386.18, \mathrm{~m} / \mathrm{z}\left[\mathrm{M}_{2} \mathrm{H}\right]^{+}=771.07\right]$ and LIGGYGFGG (b, m/z $\left.[\mathrm{MH}]^{+}=840.27\right)$; some unspecific cleavage at G $\downarrow$ Y to produce GGPVGLIGG (c, m/z $[\mathrm{MH}]^{+}=726.33$ ) was also observed. (B) OGP3: three peaks were chromatographically separated whose mass spectra were consistent with minor and unspecific cleavage of the parent peptide, which remained as the major component of the incubation mixture after $24 \mathrm{~h}$ (f, $\mathrm{m} / \mathrm{z}[\mathrm{MH}]^{+}=1207.40, \mathrm{~m} / \mathrm{z}\left[\mathrm{MH}_{2}\right]^{2+}=604.20$ ); fragments detected as minor components were YGFGG $\left(\mathrm{d}, \mathrm{m} / \mathrm{z}[\mathrm{MH}]^{+}=500.13, \mathrm{~m} / \mathrm{z}\left[\mathrm{M}_{2} \mathrm{H}\right]^{+}=998.87\right)$ and GGGIVGPLG (e, $\mathrm{m} / \mathrm{z}[\mathrm{MH}]^{+}=726.33$ ), arising from unspecific cleavage at $\mathrm{G} \downarrow \mathrm{Y}$.
1207.34), was present at the moment of incubation; also, when peptides were incubated in DPBS without enzyme, their integrity was fully maintained, demonstrating their hydrolytic stability (data not shown). After $24 \mathrm{~h}$ of incubation with MMP-2, and in the case of OGP2, the original sequence was present in only minute amounts in the recovered sample, whereas two major fragments were detected with retention times of 9.70 and 14.06 min whose mass spectra were respectively compatible with sequences GGPVG and LIGGYGFGG (Fig. 1A), as expected from MMP-2-mediated cleavage at the predicted scissile bond ( $G \downarrow L$, see Table 1 ). Some unspecific cleavage seemed to have also occurred at $\mathrm{G} \downarrow$, as suggested by the minor peak co-eluting with the remainder of the original OGP-2 sequence at $14.85 \mathrm{~min}$, and whose mass spectrum was compatible with fragment GGPVGLIGG (Fig. 1A). In what concerns OGP3, the presence of the original peptide sequence in considerable amounts could be confirmed by the fact that the major component of the recovered sample, with a retention time of $15.02 \mathrm{~min}$, presented a mass spectrum whose base-peak matched OGP-3 molecular ion at m/z 1207.40 (Fig. 1B); still, minor peaks were eluted at 13.44 and 12.38 min (Fig. 1B), whose mass spectra were respectively compatible with fragments GGGIVGPLG $\left(\mathrm{m} / \mathrm{z}[\mathrm{MH}]^{+}=\right.$ 726.33) and YGFGG $\left(\mathrm{m} / \mathrm{z}[\mathrm{MH}]^{+}=500.13\right)$. Again, this is consistent with unspecific cleavage of OGP3 between G and Y (see Table 1). According to Turk et al. [34], the scissile bond at GY might in fact exhibit some susceptibility to MMP-2 digestion, although much lower than that of GL in PVGLIG. Interestingly, this unspecific G $\downarrow$ Y cleavage will also result in the release of YGFGG (OGP10-14).

Peptide cleavage kinetics was further analyzed using FRET-peptides. These exhibit internal fluorescence quenching when intact, but emit fluorescence once cleaved [35], providing a useful tool to monitor peptide digestion in real-time. The increase in emitted fluorescence (RFUs) along the first hour of incubation is presented in Fig. 2A and B. In both cases, no hydrolysis occurred in DPBS without MMP-2, and both peptides were cleaved in FBS, even in the absence of added MMP-2. However, while cleavage of OGP2 increased in the presence of MMP-2, this was not observed with OGP3. The fluorescence emitted by the two FRET-OGP analogs when incubated in DPBS with or without MMP-2 was measured again after $48 \mathrm{~h}$ of incubation (Fig. 2C). In accordance with the previous results obtained using the fluorescamine assay, some cleavage of OGP3 occurred in the presence of MMP-2, but OGP2 was cleaved to a much higher extent.

The two OGP analogs were cleaved in the presence of FBS, suggesting that both may be hydrolyzed to some extent by indeterminate serum proteases. Under in vitro (cell cultures) and in vivo conditions, this feature may account for unspecific OGP release from both peptides. Similar observations have been previously reported by Chau et al. [36-38], who designed two dextran-peptide-methotrexate (MTX) conjugates for tumor targeting, where the peptide linkers corresponded to the same sequences used in this study (PVGLIG and GIVGPL) [36-38]. In vitro, GIVGPL-dextran conjugates were only minimally hydrolyzed by MMP-2, and PVGLIG-dextran conjugates released the drug in the presence of MMP-2, but remained intact in all the serum-containing conditions [38]. However, in vivo, in a more complex proteolytic scenario [37], drug release also took place via cleavage by lysosomal enzymes, which were able to degrade both peptide linkers, leading to nonspecific drug (MTX) release. This probably accounted for the tumor-inhibiting ability of MTX-GIVGPL-dextran conjugate, despite its lack of sensitivity towards MMPs [37].

As shown in Fig. 3, OGP2 retained the susceptibility to MMP-2cleavage in alginate-conjugated form (OGP2-Alg). Similarly to that observed with the free peptides, OGP3-Alg was also cleaved to some extent, but at a slower rate.

Overall, this part of the study provided proof-of-concept on the correct design of protease sensitive OGP2-Alg conjugates, in the sense that, as expected, these were sensitive to MMP-2 mediated cleavage. Yet, both OGP-Alg may be useful platforms for the delivery of OGP10-14like fragments. 
3.2. Effect of free and alginate-conjugated OGP analogs in hMSCs: in vitro screening studies

To assess the bioactivity of OGP analogs, hMSCs were cultured in the presence of free peptides (added to serum-free culture medium) or OGP-Alg conjugates (used as culture substrates in the form of hydrogel films), and cell proliferation was analyzed by the ${ }^{3} \mathrm{H}-\mathrm{TdR}$ assay. Cells were cultured in serum-free conditions to measure the direct action of OGP analogs on hMSCs proliferation without masking effects from serum-OGP. As soluble peptides, the classical forms of OGP and OGP10-14 have been shown to regulate the proliferation of osteoblastic and stromal cells in a biphasic-dependent manner, indicative of an autocrine/paracrine mode of action [7,14]. As depicted in Fig. 4, we were also able to demonstrate that all the OGP analogs tested in this study enhanced hMSCs proliferation after $24 \mathrm{~h}$ in relation to the control (culture medium with $0.5 \% \mathrm{v} / \mathrm{v}$ FBS).

The effect of OGP-Alg conjugates was analyzed using OGP-releasing (OGP2) vs. non-releasing (OGP1) formulations, to evaluate the importance of OGP availability on its bioactivity. The tested hydrogels also contained RGD to promote cell adhesion to the films, and RGD-Alg was used as a control. As depicted in Fig. 4, no significant differences were observed between the different groups after $24 \mathrm{~h}$. However, after

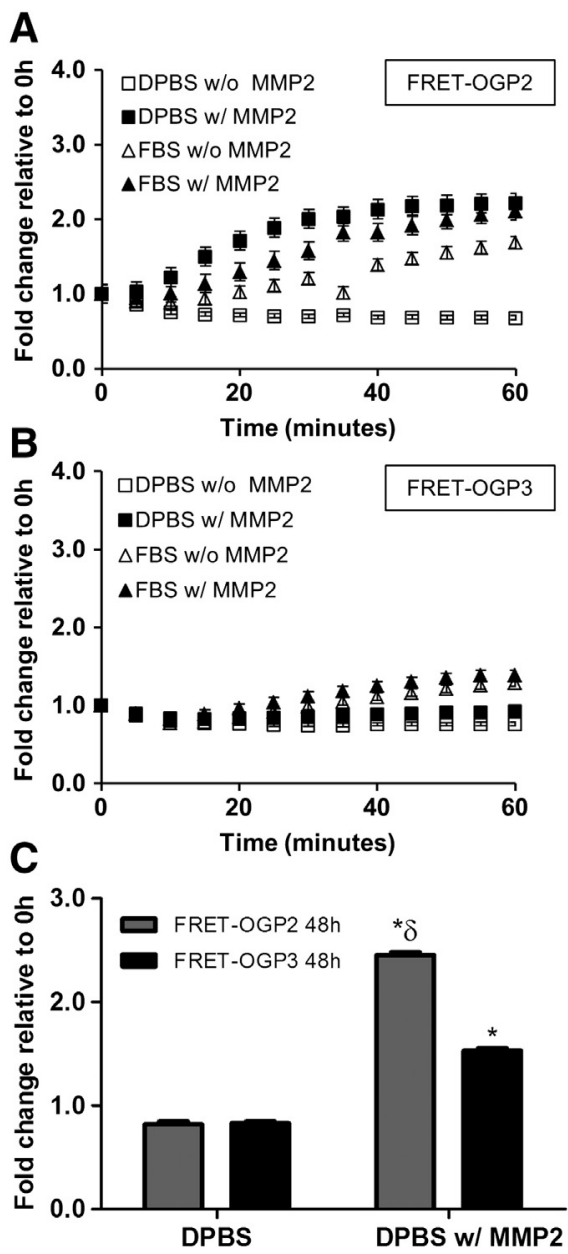

Fig. 2. FRET analysis of OGP analog cleavage. Kinetics of (A) FRET-OGP2 and (B) FRETOGP3 cleavage along $1 \mathrm{~h}$ of incubation in DPBS or FBS, with or without MMP-2 (10 nM). Samples were maintained in the microplate reader at $37{ }^{\circ} \mathrm{C}$ and the emitted fluorescence was monitored in real time. Results are presented as fold change in relation to time 0 , as mean $\pm S D(n=3)$. The extent of enzymatic cleavage after $48 \mathrm{~h}$ of incubation $\left(37^{\circ} \mathrm{C}\right)$ in DPBS with and without MMP-2 is depicted for (C) FRET-OGP2 and FRET-OGP3. Results are presented as fold change in relation to the control (without MMP-2) as mean \pm SD $(n=3)$. Symbols denote statistically significant differences in relation to $\left(^{*}\right)$ DPBS $(\mathrm{p}=0.05)$ and $(\delta)$ FRET-OGP3 $48 \mathrm{~h}(\mathrm{p}=0.05)$
$48 \mathrm{~h}$, both OGP analogs enhanced hMSCs proliferation in relation to the control. This effect was even more pronounced after $72 \mathrm{~h}$ for OGP2-Alg, but it was no longer observed with OGP1-Alg, suggesting that the availability of the active fragment, which increases upon release, may be important for its bioactivity. This is consistent with previous studies demonstrating the low impact of surface-immobilized OGP10-14 on pre-osteoblastic MC3T3-E1 cell proliferation [17].

To evaluate the effect of OGP analogs on hMSCs differentiation only free peptides were used, as the stability of alginate hydrogel films was lost after 7 days in culture, compromising the ALP assay. After 1 week of culture in BM, ALP activity was increased in the presence of OGP, except when OGP2 was used at $10^{-5} \mathrm{M}$. In OM, ALP activity increased dramatically in the presence of OGP2, especially when present at $10^{-12} \mathrm{M}$, a concentration that has been defined as being within the optimal effective range in previous studies, and which typically lies between $10^{-13} \mathrm{M}$ and $10^{-8} \mathrm{M}[7,14,39]$.

\subsection{In vivo studies with hMSCs-laden OGP-alginate hydrogels}

After confirming that both OGP2 and OGP3 analogs release bioactive YGFGG-like fragments, the in vivo performance of alginate hydrogels as depots for local co-delivery of OGP and hMSCs was evaluated. The adequacy of this type of hydrogels for hMSCs entrapment has been previously demonstrated in vitro, namely in terms of their ability to preserve cell viability and support osteogenic differentiation [30,40, 41 ], and also in vivo [22]. For this first set of studies, implants were performed at an ectopic site instead of a bone defect, to mitigate the effect of osteoinductive signals intrinsically present at the bone compartment, and to more specifically evaluate the direct impact of OGP analogs on hMSCs. Both OGP-releasing analogs were tested (OGP2/RGD-Alg and OGP3/RGD-Alg hydrogels) and RGD-Alg hydrogels were used as a control. Given the previous in vitro results, both OGP-hydrogels were expected to locally release a bioactive portion of OGP, via proteolytic cleavage of the peptide linkers, albeit at different rate: a faster release from OGP2-Alg, which incorporates the MMP-sensitive PVGLIG linker, was anticipated.

\subsubsection{Hydrogel degradation, host tissue invasion and vascularization}

The degradation pattern of implanted cell-laden hydrogels was first characterized, as it is a relevant determinant of their in vivo performance. Ideally, it should take place within a balanced time frame. It should not prevent cell release, or impede the invasion of host tissue, but should allow the deposition of new ECM before the complete disintegration/dissolution of the hydrogels. As depicted in Figs. 5, 4 weeks after implantation it was still possible to localize a high density



Fig. 3. OGP release from OGP-Alg hydrogels. The fluorescamine assay was used to determine the amount of free amine groups present in the supernatant, which increases as the peptides are cleaved, releasing OGP-like fragments. Results are presented as fold change in relation to $t=0$ as mean values $\pm \operatorname{SD}(n=3)$. Symbols denote statistically significant differences in relation to $\left({ }^{*}\right) \mathrm{w} / \mathrm{o}$ MMP2 $(\mathrm{p}=0.0383)$ and $(\delta)$ OGP3 $(\mathrm{p}=0.0383)$. 


\section{A}

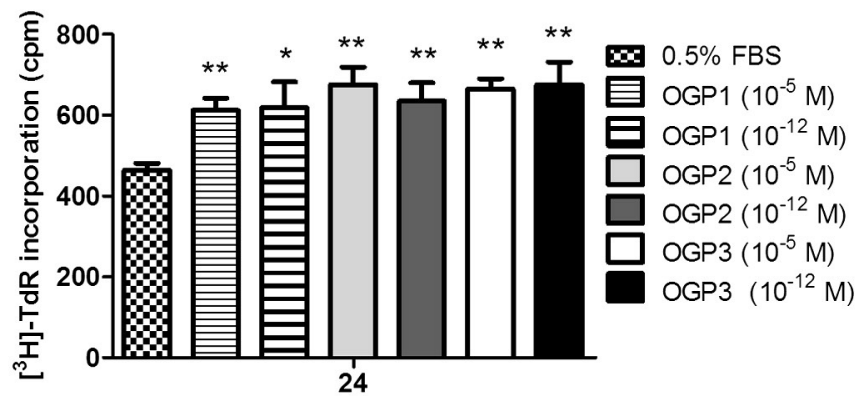

Time (hours)

B

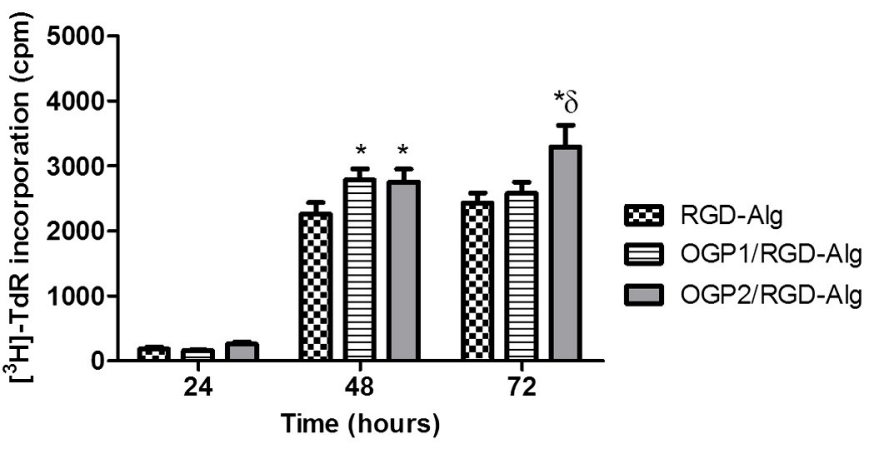

C

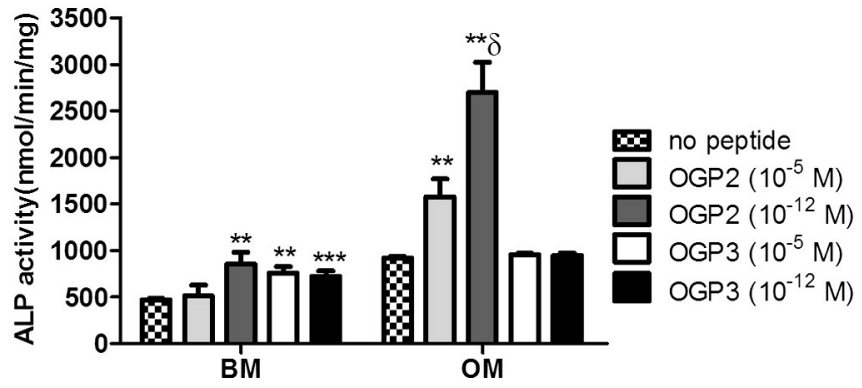

D

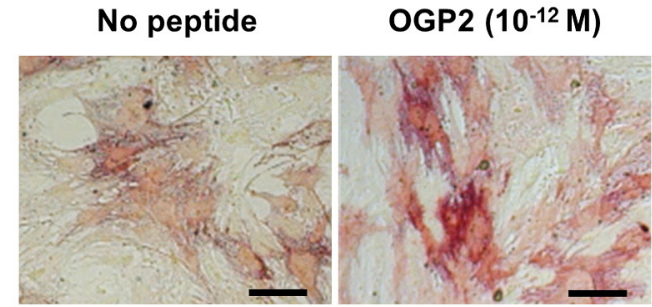

Fig. 4. Effect of free and Alg-conjugated OGP analogs on hMSCs behavior. (A, B) Cell proliferation upon exposure for $24 \mathrm{~h}$ to (A) free or (B) Alg-conjugated OGP analogs, assessed by the ${ }^{3} \mathrm{H}$-TdR assay. (C) Expression of ALP activity by hMSCs after 7 days of culture in the presence of free OGP analogs $\left(10^{-5} \mathrm{M}\right.$ or $\left.10^{-12} \mathrm{M}\right)$ added to BM or OM. Cells cultured in the absence of peptides were used as controls. Symbols denote statistically significant differences in relation to: $\left({ }^{*}\right)$ no peptide within BM or OM group $\left({ }^{* *} \mathrm{p}<0.02\right.$; $\left.{ }^{* * *} \mathrm{p}<0.005\right)$; and $(\delta)$ OGP2 $\left(10^{-5} \mathrm{M}\right)$. (D) ALP staining of control and OGP2 $\left(10^{-12} \mathrm{M}\right)$-treated hMSCs cultures in TCPS under OM (scale bar $\left.=100 \mu \mathrm{m}\right)$.

of hMSCs inside the peptide-alginate carriers. Hydrogel fragmentation and host tissue invasion (blue-green) were detected in all samples, but were more significant in OGP groups, probably because the stiffness ( $G$ ', elastic component of the shear moduli) of these hydrogels was slightly lower than that of the control hydrogels, as determined by


Fig. 5. In vivo degradation and host tissue invasion of peptide-Alg hydrogels. (A) Images of Safranin-O/Fast green-stained paraffin-sections of hMSCs-laden Alg hydrogels (Alg in orange-red, connective tissue in blue-green) at day 0 (scale bar: $100 \mu \mathrm{m}$ ), or after 28 days of implantation within the different hydrogels (scale bar: $1 \mathrm{~mm}$ ). (B) Lower magnification images of the explanted hMSCs-laden Alg hydrogels. (C) Quantitative analysis of host tissue invasion (\% of blue area per disc) at day 28. Alginate fragmentation/host tissue invasion was more significant in OGP groups. Data is presented as mean $\pm S D$ ( $n=4$ mice, 2 sections per mice), ${ }^{*}$ denotes statistical significant differences in relation to control ( $\mathrm{p}=$ 0.0104). (For interpretation of the references to color in this figure legend, the reader is referred to the web version of this article.)

oscillatory shear rheometry (supplementary data). Increased implant degradation in the presence of immobilized OGP peptides has been reported in previous studies, where these were used as covalent crosslinkers for amino acid-based poly (ester urea) materials [42]. In that case, the higher degradation was explained by the additional free volume in the polymer plugs imparted by the OGP crosslinker and increased swelling due to the presence of peptides [42]. The pattern of connective tissue (blue-green) deposition by host cells did not evidence the classical fibrous capsule formation, with organized fibers around a non-degradable implant, and instead resembled a reorganization of the matrix as the material is degraded, which would be anticipated and is beneficial in a regeneration scenario. We observed a similar outcome in a previous study where alginate hydrogels were implanted in the same animal model [22]. The progressive degradation of the hydrogel matrices is expected to result in the release of hMSCs over time (Section 3.3.2), and in the diminution of their 3D confinement, which 




B


Fig. 6. Implant vascularization and VEGF 165 expression by transplanted hMSCs. (A) Perfused blood vessels (black arrows) at the implant site were identified by MT-staining (erythrocytes in red; * Alg in pale blue; host tissue in green/blue; the dashed line represents host tissue/Alg interface, the OGP3 group is presented as an example; scale bar: $10 \mu \mathrm{m}$ ). (B) Quantitative analysis of the average number of vessels at the implant site. Data is presented as mean $\pm S D$ ( $n=4$ mice, 6 sections per mice). (C) Expression of VEGF $_{165}$ mRNA by transplanted hMSCs analyzed by qRT-PCR $(\mathrm{n}=3$ mice). Results were normalized internally with GAPDH. Symbols denote statistically significant differences in relation to $\left({ }^{*}\right)$ RGD-Alg $(p=0.004)$ and $(\delta)$ OGP2/RGD-Alg $(p=0.0359)$. (For interpretation of the references to color in this figure legend, the reader is referred to the web version of this article.)

will be important for prolonged viability. In the future studies, further optimizations of the current system may be envisaged, for example, via inclusion of the protease-sensitive peptides as crosslinking moieties, which would allow cells to remodel their pericellular area and create additional space to migrate, proliferate and synthesize new ECM [22].

Perfused blood vessels were detected at the implant site in all groups, located mainly within the newly formed tissue but also within the hydrogels (Fig. 6A, where the OGP3 group is depicted as an example). Neo-vascularization was enhanced in OGP3/RGD-Alg, compared to the other groups tested (Fig. 6). It is well accepted that proper vascularization is a prerequisite for the survival of transplanted cells and new tissue formation. Also, it is well established that there is a key interplay between angiogenesis and osteogenesis [21]. So, an osteoinductive compound capable of also stimulating neo-vessel formation would certainly represent a promising therapeutic agent for bone regeneration. Interestingly, an effect of OGP on implant vascularization has been recently reported [42], but the underlying mechanisms remained unclear and, to our knowledge, the authors have not further investigated this phenomenon. In another study, Bocci et al. demonstrated the lack of mitogenic and pro-adhesive activity of OGP on microvascular endothelial cell cultures [43]. Here, we investigated whether the level of neo-vascularization correlated with the secretion of proangiogenic factors by transplanted hMSCs [44], and examined the expression of vascular endothelial growth factor $165\left(\mathrm{VEGF}_{165}\right)$, which represents one of the most potent endothelial cell mitogens. Unexpectedly, our results revealed higher VEGF $_{165}$ mRNA expression in the OGP2/RGD-Alg group, as compared to the other groups, which also exhibited higher angiogenic potential in a chick embryo chorioallantoic membrane (CAM) assay (supplementary data). So, most probably, the OGP3/RGD-Alg matrices are more vascularized simply because their faster degradation facilitated the ingrowth of neo-vessels.

\subsubsection{ECM production and cell proliferation at the implant site}

ECM deposition (COL1) at the implant site was detected in all the formulations (Fig. 7). OGP groups, especially OGP3/RGD-Alg, stained more intensely for COL1 than the control, and the new collagenous matrix appeared more uniformly distributed throughout the implant area. Within the hydrogels, COL1 was detected intracellularly and in the pericellular space, indicating that transplanted hMSCs were able to produce and secrete their own ECM.

To evaluate the effect of OGP on cell proliferation, transplanted hMSCs were distinguished from mouse cells by immunolabeling using a human nuclei-specific antibody (HuNu). Although the in vitro studies with hMSCs cultures demonstrated a mitogenic effect for all the tested OGP analogs in their soluble form and as OGP-Alg hydrogel films, we have not been able to demonstrate any significant outcome of OGP2 or OGP3 on cell proliferation in vivo, at least after 4 weeks of implantation (Fig. 8). A few proliferating cells (Ki67+), both from human $(\mathrm{HuNu}+\mathrm{hMSCs})$ and mouse $(\mathrm{HuNu}-$ cells) origins, have been detected within the hydrogel and adjacent host tissue, but there was no statistically significant difference between groups in terms of \% of
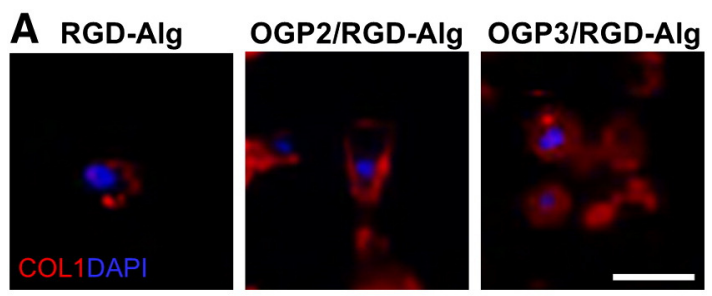

\section{B}

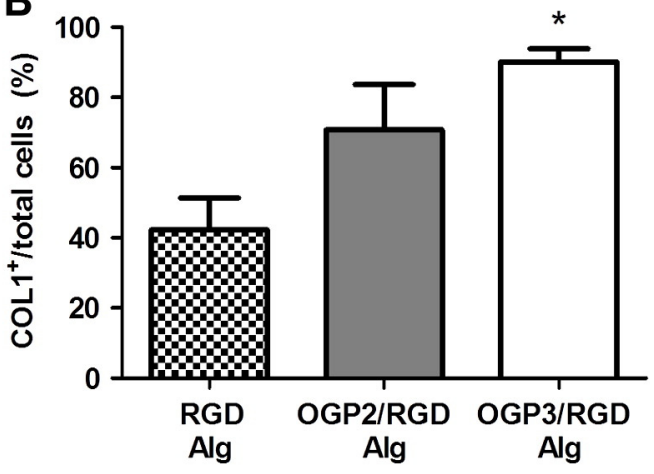

Fig. 7. Expression of collagen type 1 at the implant site. (A) Representative images of COL1 (in red) expression on tissue sections from the different groups at day 28 (scale bar: $10 \mu \mathrm{m}$ ). (B) Quantification of \% of COL1 + cells relative to the total number of cells. Data is presented as mean $\pm \mathrm{SD}$ ( $\mathrm{n}=4$ mice, 4 sections per mice), ${ }^{*}$ denotes statistical differences in relation to the control ( $\mathrm{p}=0.0019$ ). (For interpretation of the references to color in this figure legend, the reader is referred to the web version of this article.) 


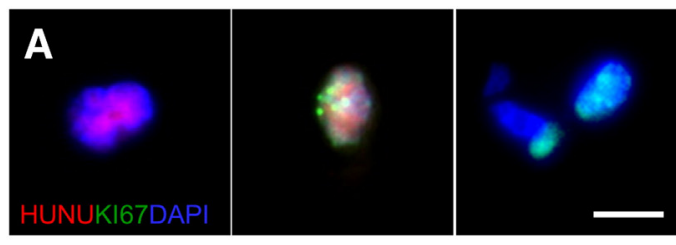

B
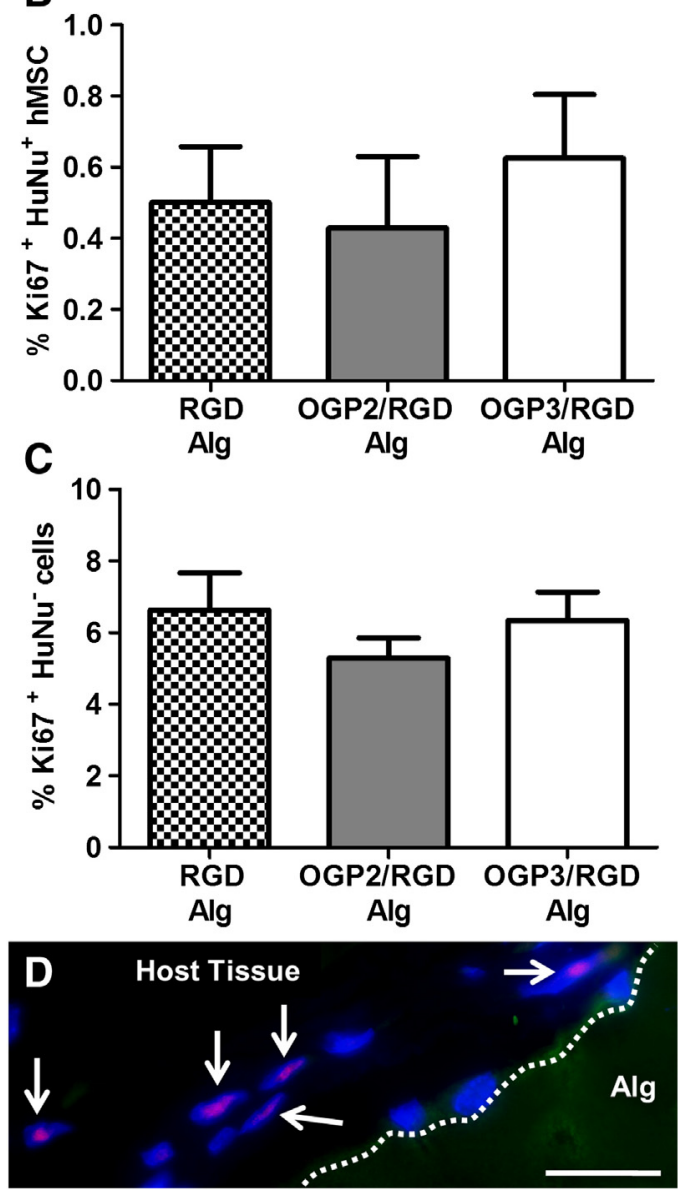

Fig. 8. Proliferative vs. non-proliferative human and mouse cells at the implant site. (A) Double immunolabeling with anti-HuNu (red) and Ki67 antibodies (green). Nuclei were counter-stained with DAPI (blue), scale bar represents $5 \mu \mathrm{m}$ : (left) HuNu + Ki67 non-proliferative hMSCs; (center) HuNu + Ki67 + proliferative hMSCs; and (right) $\mathrm{HuNu}-\mathrm{Ki} 67+$ proliferative mice cells (B) percentage of proliferative hMSCs (HuNu + Ki67+) in relation to total hMSCs $(\mathrm{HuNu}+)$. (C) Percentage of proliferative mice cells $(\mathrm{HuNu}-\mathrm{Ki} 67+)$ in relation to total mice cells $(\mathrm{HuNu}-)$. Data is presented as mean \pm $\mathrm{SD}$ ( $\mathrm{n}=4$ mice, 4 sections per mice). (D) HuNu + cells (arrows) were also detected outside, integrated in the host tissue. The dashed line represents tissue/alginate interface. (For interpretation of the references to color in this figure legend, the reader is referred to the web version of this article.)

proliferating cells, even if mean values were slightly higher in OGP3 group. This may be in part related with the follow-up time frame. Possibly, OGP analogs may increase cell proliferation in an early stage in the regenerative process but, after 4 weeks of implantation, hMSCs were probably already transiting from a proliferative to a maturation phase,

Fig. 9. Osteogenic differentiation of transplanted hMSCs. (A) qRT-PCR analysis of Runx2, ALP and OCN mRNA expression. Data is presented as mean $\pm \mathrm{SD}(\mathrm{n}=3$ mice $),\left({ }^{*}\right)$ denotes statistical significant differences $(\mathrm{p}=0.038)$ relative to RGD-Alg control. Results were normalized internally with GAPDH. (B) Histological analysis of collagenous matrix deposition (Masson's trichrome staining; blue color indicates collagen deposition, * represents alginate) and matrix mineralization (alizarin red staining; red color indicates calcium deposition, * represents alginate), which were detected in all groups (image at the center, OGP2; higher magnification images at the bottom, all formulations). (For interpretation of the references to color in this figure legend, the reader is referred to the web version of this article.)
A


B



C

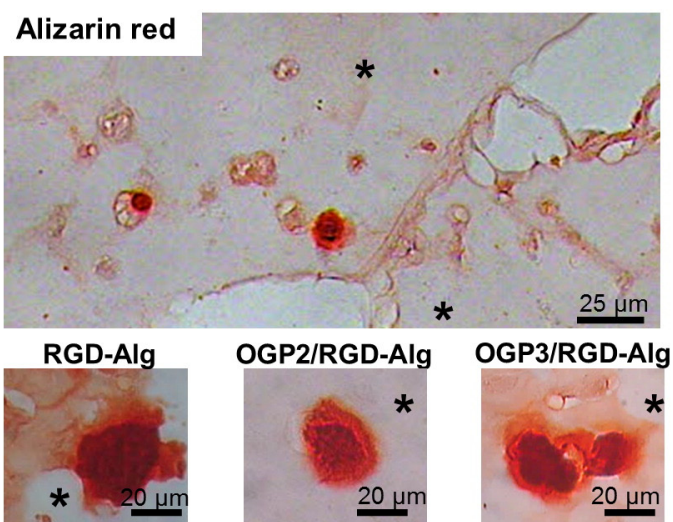


which seems to correlate with our data on hMSCs expression of lineagespecific genes (see below). A transitory effect of surface-immobilized OGP and OGP10-14 on cell proliferation has been previously shown in osteoblastic MC3T3-E1 cultures, where a positive outcome was observed at day 3, but was no longer seen at day 7 when cells were presumably in a more mature state [17].

Noteworthy, the human-nuclei specific labeling allowed us to confirm that transplanted hMSCs were located not only inside the alginate matrix, but also outside, integrated in the host tissue (Fig. 8D), demonstrating that the hydrogels effectively acted as cell-delivery systems.

\subsubsection{Osteogenic differentiation of transplanted hMSCS}

Differentiation of transplanted hMSCs was analyzed by quantifying mRNA expression of Runx2, ALP and OCN osteogenic markers (Fig. 9). In what concerns the expression of Runx 2 and OCN, a key osteoblast transcription factor and its target gene, respectively, we found higher levels of OCN expression in OGP groups, with a concomitant decrease in Runx2 expression, which is consistent with published results on the temporal mRNA expression of these two bone-specific markers during the development of the osteoblast phenotype in MC3T3-E1 cultures [45]. The expression of ALP mRNA was also detected in all samples, being higher in OGP2/RGD-Alg than in the other groups. Taken together, these results demonstrated that hMSCs within OGP-releasing hydrogels were in a more mature stage of osteoblastic differentiation, as compared to the control, suggesting that the immobilized OGP peptides retained their bioactivity. Osteogenic differentiation of transplanted hMSCs in all groups was also confirmed at the protein level by histological analysis (Fig. 9B and C), which showed that hMSCs were able to produce and deposit an endogenous collagenous matrix (Masson's trichrome staining) at their pericellular space, and were also able to mineralize it (alizarin red staining). An effect of OGP on OCN expression has been previously demonstrated in other in vivo experimental settings, namely during healing of femoral fractures in rats [12]. After parental administration of OGP for 1 week, systemic and local mRNA expression of different growth factors were examined after 1, 2, 3 and 4 weeks [12]. Local expression of OCN increased earlier in the OGP-treated group, and its systemic expression remained increased throughout the 4-week period [12].

One recognized limitation of this study is that all groups have been implanted in the same animal. Thus, circulating peptides released from OGP-hydrogels may have had a systemic effect, affecting also the response observed in the control group. Even so, overall, the most promising results were obtained with the OGP groups, confirming our initial hypothesis on the significance of OGP/hMSCs co-delivery systems. Differences between the two OGP analogs may be related with their different release kinetics and/or the potency of the released bioactive fragment (LIGGYGFGG in OGP2 and YGFGG in OGP3).

This and other open questions should be addressed in future experiments. In particular, it will be essential to test the proposed system using clinically relevant models, such as critical-sized bone defects or bone fractures, where the effect of locally delivered OGP may be potentiated by the adjuvant action of osteoinductive stimuli, naturally present in the bone compartment.

\section{Conclusions}

This study provided proof-of-concept on the correct design of OGP-Alg conjugates with protease-sensitive linkers, and demonstrated their usefulness as a platform for the in situ co-delivery of synthetic OGP analogs and hMSCs. Two different peptides were tested and both showed interesting effects. While in vitro OGP2 presented better results probably due to increased bioavailability, a positive in vivo outcome was obtained with both OGP analogs. Importantly, we demonstrated that the local co-delivery of bioactive OGP analogs and hMSCs from injectable hydrogels promoted the osteogenic differentiation of transplanted
hMSCs in an ectopic setting. This novel strategy might provide a useful alternative for minimally invasive healing of small bone defects.

\section{Acknowledgements}

This work was financed by FEDER funds through the Programa Operacional Factores de Competitividade (COMPETE) and by Portuguese funds through Fundação para a Ciência e a Tecnologia (FCT), in the framework of the projects Pest-C/SAU/LA0002/2011 and BIOMATRIX (PTDC/ SAU-BEB/101235/2008 and FCOMP-01-0124-FEDER-010915), and cofinanced by North Portugal Regional Operational Programme (ON.2-O Novo Norte) in the framework of project SAESCTN-PIIC\&DT/2011, under the National Strategic Reference Framework (NSRF). PG and NV thank FCT and FEDER (European Union) for funding through project grants CONC-REEQ/275/QUI and PEst-C/QUI/UI0081/2011. NV also thanks FCT for Post-Doc grant SFRH/BPD/48345/2008. FM acknowledges INL-International Iberian Nanotechnology Laboratory for her $\mathrm{PhD}$ scholarship. CB has a research position funded by FCT-POPH-FSE (Ciência 2008). The authors are also grateful to $\mathrm{Dr}^{\mathrm{a}}$ Maria Aparecido (UNIFESP, Brazil) for providing the FRET peptides.

\section{Appendix A. Supplementary data}

Supplementary data to this article can be found online at http://dx. doi.org/10.1016/j.jconrel.2014.06.030.

\section{References}

[1] A. Parisi-Amon, W. Mulyasasmita, C. Chung, S.C. Heilshorn, Protein-engineered injectable hydrogel to improve retention of transplanted adipose-derived stem cells, Adv. Healthc. Mater. 2 (2013) 428-432.

[2] T.N. Vo, F.K. Kasper, A.G. Mikos, Strategies for controlled delivery of growth factors and cells for bone regeneration, Adv. Drug Deliv. Rev. 64 (2012) 1292-1309.

[3] A.J. Firestone, J.K. Chen, Controlling destiny through chemistry: small-molecule regulators of cell fate, ACS Chem. Biol. 5 (2009) 15-34.

[4] F.R. Maia, S.J. Bidarra, P.L. Granja, C.C. Barrias, Functionalization of biomaterials with small osteoinductive moieties, Acta Biomater. 9 (2013) 8773-8789.

[5] I. Bab, H. Gavish, M. Namdar-Attar, Z. Greenberg, Y. Chen, N. Mansur, et al., Isolation of mitogenically active C-terminal truncated pentapeptide of osteogenic growth peptide from human plasma and culture medium of murine osteoblastic cells, J. Pept. Res. 54 (1999) 408-414.

[6] I. Bab, M. Chorev, Osteogenic growth peptide: from concept to drug design, Pept. Sci. 66 (2002) 33-48.

[7] Z. Greenberg, H. Gavish, A. Muhlrad, M. Chorev, A. Shteyer, M. Attar-Namdar, et al., Isolation of osteogenic growth peptide from osteoblastic MC3T3 E1 cell cultures and demonstration of osteogenic growth peptide binding proteins, J. Cell. Biochem. 65 (1997) 359-367.

[8] I. Bab, D. Gazit, C. Yu-Chen, A. Muhlrad, A. Shteyer, M. Chorev, Synthetic Peptides and Pseudopeptides Having Osteogenic Activity and Pharmaceutical Compositions Containing the Same, US 6,479,460 B1 Yissum Research Development Company of the Hebrew University of Jerusalem, 2002.

[9] N. Gabarin, H. Gavish, A. Muhlrad, Y.-C. Chen, M. Namdar-Attar, R.A. Nissenson, et al. Mitogenic Gi protein-MAP kinase signaling cascade in MC3T3-E1 osteogenic cells: activation by C-terminal pentapeptide of osteogenic growth peptide [OGP(10-14)] and attenuation of activation by cAMP, J. Cell. Biochem. 81 (2001) 594-603.

[10] S.M.S. Miguel, M. Namdar-Attar, T. Noh, B. Frenkel, I. Bab, ERK1/2-activated de novo Mapkapk2 synthesis is essential for osteogenic growth peptide mitogenic signaling in osteoblastic cells, J. Biol. Chem. 280 (2005) 37495-37502.

[11] L. Mattii, B. Battolla, S. Moscato, R. Fazzi, S. Galimberti, N. Bernardini, et al., The small peptide OGP(10-14) acts through Src kinases and RhoA pathways in Mo-7e cells: morphologic and immunologic evaluation, Med. Sci. Monit. 14 (2008) BR103-BR108.

[12] M.A. Brager, M.J. Patterson, J.F. Connolly, Z. Nevo, Osteogenic growth peptide normally stimulated by blood loss and marrow ablation has local and systemic effects on fracture healing in rats, J. Orthop. Res. 18 (2000) 133-139.

[13] Y. Gabet, R. Müller, E. Regev, J. Sela, A. Shteyer, K. Salisbury, et al., Osteogenic growth peptide modulates fracture callus structural and mechanical properties, Bone 35 (2004) 65-73.

[14] D. Robinson, I. Bab, Z. Nevo, Osteogenic growth peptide regulates proliferation and osteogenic maturation of human and rabbit bone marrow stromal cells, J. Bone Miner. Res. 10 (1995) 690-696.

[15] Z.-X. Chen, M. Chang, Y.-1. Peng, L. Zhao, Y.-r. Zhan, L.-j. Wang, et al., Osteogenic growth peptide C-terminal pentapeptide [OGP(10-14)] acts on rat bone marrow mesenchymal stem cells to promote differentiation to osteoblasts and to inhibit differentiation to adipocytes, Regul. Pept. 142 (2007) 16-23.

[16] L.S. Mendes, S. Saska, M.A. Martines, R. Marchetto, Nanostructured materials based on mesoporous silica and mesoporous silica/apatite as osteogenic growth peptide carriers, Mater. Sci. Eng. C Mater. Biol. Appl. 33 (2013) 4427-4434. 
[17] N.M. Moore, N.J. Lin, N.D. Gallant, M.L. Becker, The use of immobilized osteogenic growth peptide on gradient substrates synthesized via click chemistry to enhance MC3T3-E1 osteoblast proliferation, Biomaterials 31 (2010) 1604-1611.

[18] A. Horii, X. Wang, F. Gelain, S. Zhang, Biological designer self-assembling peptide nanofiber scaffolds significantly enhance osteoblast proliferation, differentiation and 3-D migration, PLoS ONE 2 (2007) e190.

[19] A. Page-McCaw, A.J. Ewald, Z. Werb, Matrix metalloproteinases and the regulation of tissue remodelling, Nat. Rev. Mol. Cell Biol. 8 (2007) 221-233.

[20] K.B. Fonseca, S.J. Bidarra, M.J. Oliveira, P.L. Granja, C.C. Barrias, Molecularly designed alginate hydrogels susceptible to local proteolysis as three-dimensional cellular microenvironments, Acta Biomater. 7 (2011) 1674-1682.

[21] S.J. Bidarra, C.C. Barrias, K.B. Fonseca, M.A. Barbosa, R.A. Soares, P.L. Granja, Injectable in situ crosslinkable RGD-modified alginate matrix for endothelial cells delivery, Biomaterials 32 (2011) 7897-7904.

[22] K.B. Fonseca, D.B. Gomes, K. Lee, S.G. Santos, E.A. Silva, D.J. Mooney, et al., Injectable MMP-sensitive alginate hydrogels as hMSC delivery systems, Biomacromolecules 15 (2014) 380-390.

[23] V. Vacharathit, E.A. Silva, D.J. Mooney, Viability and functionality of cells delivered from peptide conjugated scaffolds, Biomaterials 32 (2011) 3721-3728.

[24] K.B. Fonseca, F.R. Maia, F.A. Cruz, D. Andrade, M.A. Juliano, P.L. Granja, et al., Enzymatic, physicochemical and biological properties of MMP-sensitive alginate hydrogels, Soft Matter 9 (2013) 3283-3292.

[25] G.B. Fields, R.L. Noble, Solid phase peptide synthesis utilizing 9fluorenylmethoxycarbonyl amino acids, Int. J. Pept. Protein Res. 35 (1990) $161-214$.

[26] J. Cortez, E. Vorobieva, D. Gralheira, I. Osório, L. Soares, N. Vale, et al. Bionanoconjugates of tyrosinase and peptide-derivatised gold nanoparticles for biosensing of phenolic compounds, J. Nanopart. Res. 13 (2011) 1101-1113.

[27] P.C. Almeida, V. Oliveira, J.R. Chagas, M. Meldal, M.A. Juliano, L. Juliano, Hydrolysis by cathepsin B of fluorescent peptides derived from human prorenin, Hypertension 35 (2000) 1278-1283.

[28] R. Garesse, J.V. Castell, C.G. Vallejo, R. Marco, A fluorescamine-based sensitive method for the assay of proteinases, capable of detecting the initial cleavage steps of a protein, Eur. J. Biochem. 99 (1979) 253-260.

[29] T. Boontheekul, H.-J. Kong, D.J. Mooney, Controlling alginate gel degradation utilizing partial oxidation and bimodal molecular weight distribution, Biomaterials 26 (2005) 2455-2465

[30] M.B. Evangelista, S.X. Hsiong, R. Fernandes, P. Sampaio, H.-J. Kong, C.C. Barrias, et al., Upregulation of bone cell differentiation through immobilization within a synthetic extracellular matrix, Biomaterials 28 (2007) 3644-3655.

[31] J.A. Rowley, G. Madlambayan, D.J. Mooney, Alginate hydrogels as synthetic extracellular matrix materials, Biomaterials 20 (1999) 45-53.

[32] E. Alsberg, H.J. Kong, Y. Hirano, M.K. Smith, A. Albeiruti, D.J. Mooney, Regulating bone formation via controlled scaffold degradation, J. Dent. Res. 82 (2003) 903-908.
[33] S.M. Oliveira, C.C. Barrias, I.F. Almeida, P.C. Costa, M.R.P. Ferreira, M.F. Bahia, et al., Injectability of a bone filler system based on hydroxyapatite microspheres and a vehicle with in situ gel-forming ability, J. Biomed. Mater. Res. Part B 87B (2008) 49-58.

[34] B.E. Turk, L.L. Huang, E.T. Piro, L.C. Cantley, Determination of protease cleavage site motifs using mixture-based oriented peptide libraries, Nat. Biotechnol. 19 (2001) 661-667.

[35] B. Korkmaz, S. Attucci, M.A. Juliano, T. Kalupov, M.L. Jourdan, L. Juliano, et al., Measuring elastase, proteinase 3 and cathepsin $\mathrm{G}$ activities at the surface of human neutrophils with fluorescence resonance energy transfer substrates, Nat. Protoc. 3 (2008) 991-1000.

[36] Y. Chau, N.M. Dang, F.E. Tan, R. Langer, Investigation of targeting mechanism of new dextran-peptide-methotrexate conjugates using biodistribution study in matrixmetalloproteinase-overexpressing tumor xenograft model, J. Pharm. Sci. 95 (2006) 542-551.

[37] Y. Chau, R.F. Padera, N.M. Dang, R. Langer, Antitumor efficacy of a novel polymerpeptide-drug conjugate in human tumor xenograft models, Int. J. Cancer 118 (2006) 1519-1526.

[38] Y. Chau, F.E. Tan, R. Langer, Synthesis and characterization of dextran-peptidemethotrexate conjugates for tumor targeting via mediation by matrix metalloproteinase II and matrix metalloproteinase IX, Bioconjug. Chem. 15 (2004) 931-941.

[39] A. Spreafico, B. Frediani, C. Capperucci, A. Leonini, D. Gambera, P. Ferrata, et al., Osteogenic growth peptide effects on primary human osteoblast cultures: potential relevance for the treatment of glucocorticoid-induced osteoporosis, J. Cell. Biochem. 98 (2006) 1007-1020.

[40] F.R. Maia, A.H. Lourenco, P.L. Granja, R.M. Goncalves, C.C. Barrias, Effect of cell density on mesenchymal stem cells aggregation in RGD-alginate 3D matrices under osteoinductive conditions, Macromol. Biosci. (2014), http://dx.doi.org/10.1002/ mabi.201300567 (n/a-n/a).

[41] F.R. Maia, K.B. Fonseca, G. Rodrigues, P.L. Granja, C.C. Barrias, Matrix-driven formation of MSC-ECM microtissues on soft alginate hydrogels, Acta Biomater. 10 (2014) 3197-3208.

[42] K.S. Stakleff, F. Lin, L.A. Smith Callahan, M.B. Wade, A. Esterle, J. Miller, et al., Resorbable, amino acid-based poly(ester urea)s crosslinked with osteogenic growth peptide with enhanced mechanical properties and bioactivity, Acta Biomater. 9 (2013) 5132-5142.

[43] G. Bocci, R. Danesi, A. Fioravanti, M. Del Tacca, The effect of osteogenic growth peptide OGP on proliferation and adhesion of HEMC-1 human endothelial cells, Pharmacol. Res. 45 (2002) 21-25.

[44] Y. Wu, L. Chen, P.G. Scott, E.E. Tredget, Mesenchymal stem cells enhance wound healing through differentiation and angiogenesis, Stem Cells 25 (2007) 2648-2659.

[45] S. Pregizer, S.K. Baniwal, X. Yan, Z. Borok, B. Frenkel, Progressive recruitment of Runx2 to genomic targets despite decreasing expression during osteoblast differentiation, J. Cell. Biochem. 105 (2008) 965-970. 